\title{
Differential Effects of Commercial-Grade and Purified Poloxamer 188 on Renal Function
}

\author{
Martin Emanuele $\cdot$ Balu Balasubramaniam
}

Published online: 11 April 2014

(c) The Author(s) 2014. This article is published with open access at Springerlink.com

\begin{abstract}
Poloxamer 188 (P188) is a non-ionic amphiphilic copolymer with hemorheologic, antithrombotic, antiinflammatory, and cytoprotective properties. It potentially has clinical utility in diverse diseases, such as acute myocardial infarction, acute limb ischemia, shock, acute stroke, heart failure, and sickle cell crisis. P188 is available as an excipient-grade product, manufactured to National Formulary specifications, which we refer to as P188-NF. During synthesis of P188-NF, polymerization of its polyoxyethylene and polyoxypropylene components generates undesirable low molecular weight (LMW) substances, such as truncated polymers and glycols. In early clinical studies, P188-NF yielded unexpected renal dysfunction. Here, we explore the nature of the renal dysfunction associated with P188-NF and use a purified (more homogenous) form of P188-NF (P188-P) to show that removal of LMW substances is associated with substantially less renal dysfunction. In both a remnant-kidney animal model and in clinical studies, P188-P demonstrates a substantially improved renal safety profile.
\end{abstract}

\section{Introduction}

Poloxamer 188 (P188) is a non-ionic amphiphilic copolymer consisting of a central chain of hydrophobic polyoxypropylene flanked at both ends by hydrophilic polyoxyethylene. The average molecular weight is about $8,500 \mathrm{kD}$ (Fig. 1). The term "poloxamer" generically

M. Emanuele $(\bowtie) \cdot$ B. Balasubramaniam

Mast Therapeutics, 12390 El Camino Real, Suite 150, San

Diego, CA 92130, USA

e-mail: memanuele@mastthera.com applies to the different triblock copolymers made by varying the lengths of the polyoxypropylene and polyoxyethylene blocks. The copolymers are commonly named with the letter "P" (for poloxamer) followed by three digits, the first two digits $\times 300$ give the approximate molecular mass of the polyoxypropylene core, and the last digit $\times 10$ gives the percentage polyoxyethylene content (e.g., P188 indicates a polyoxypropylene molecular mass of $5,400 \mathrm{~g} / \mathrm{mol}$ and $80 \%$ polyoxyethylene content).

P188 binds to damaged cell membranes in areas of decreased lipid density, promoting stability and restoring membrane barrier function $[1,2]$. In addition to these direct effects on membrane integrity, $\mathrm{P} 188$ has been shown to almost completely prevent lipid peroxidation induced by $\mathrm{Fe}^{2+}$ and $\mathrm{H}_{2} \mathrm{O}_{2}$ [3]. P188 binding serves to maintain the asymmetric distribution of phospholipids within cell membranes, preventing the "flip-flopping" and surface exposure of phosphatidylserine, without which the initiation of coagulation or the recognition process leading to the clearance of apoptotic cells is blocked [4]. Stopping transmembrane phospholipid redistribution is also known to hinder red blood cell transformation to echinocytes (i.e., echinocytosis) and release of membrane microparticles (i.e., microvesiculation) [5]. Membrane-bound P188 also reduces surface tension and hydrophobic-based cellular adherence, which can hinder the free movement of blood cells within the vasculature and initiate thrombotic and inflammatory cascades [6, 7]. Video microscopy demonstrates that P188 improves the elastic properties of red blood cells, improving their deformability and increasing their ability to pass through small channels often smaller than the red blood cell diameter [8]. Its biophysical properties also account for its widespread use as a surfactant in the preparation of nanoparticles and micelles to transduce various payloads into cells $[9,10]$. 


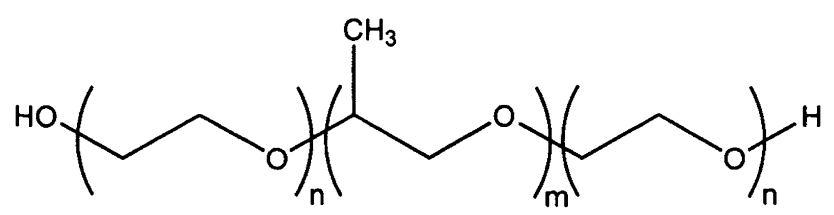

ethylene oxide propylene oxide ethylene oxide

Fig. 1 Chemical formula for poloxamer 188 (P188). With $n=80$ and $m=27, \mathrm{P} 188$ has a calculated molecular weight of $8,624 \mathrm{kD}$

An accumulating number of studies suggest that P188 has potential clinical utility, particularly in conditions characterized by poor microvascular blood flow or where cellular function may be compromised by a damaged cell membrane [11-14]. P188 exhibits clinically desirable hemorheologic properties, reducing blood viscosity $[15,16]$ and red blood cell aggregation [17, 18]. When used in combination with tissue plasminogen activator or streptokinase, it markedly increases fibrinolysis [19, 20]. In models of acute myocardial infarction (AMI), P188 reduced the infarct size by $40-50 \%$ and improved the left ventricular ejection fraction by about $30 \%$ [21, 22]. Although it is not an anticoagulant, P188 has been shown to diminish thrombotic coronary occlusion after arterial injury and stent placement in a porcine model [23]. It induced normal perfusion (Thrombolysis in Myocardial Infarction [TIMI] grade 3 flow) following primary percutaneous transluminal coronary angioplasty following acute myocardial infarction [24]. In models of experimental shock, P188 significantly improved the median survival time in miniature swine after severe controlled hemorrhage, compared with that observed in controls $(p=0.0186)$ [25]. Zhang et al. [26] evaluated P188 in multiple rat models of hemorrhagic shock. In these studies, P188 improved survival $(p<0.001)$, as well as significantly decreasing the fluid requirements required to regain and maintain hemodynamic performance goals $(p=0.0002)$ and reducing tissue permeability/fluid extravasation in the lung and small intestine $(p<0.01)$, while maintaining core organ perfusion and reducing markers of inflammation and apoptosis. In other animal models of ischemia/reperfusion injury, P188 preserved the integrity of neuronal cell membranes, as well as the integrity of the blood-brain barrier. Control mice subjected to transient focal ischemia showed numerous propidium iodide (PI)-labeled cells in ischemic areas, including the hippocampus and striatum, but no PI-positive cells were detected in the contralateral hemisphere. P188 treatment significantly reduced the PI-positive cells in the hippocampus and striatum area [27]. More recently, phase 2 and 3 studies in patients with sickle cell crisis have shown that treatment with P188 is associated with a reduction in the duration of crisis $[28,29]$.
P188 is available as an excipient-grade product, manufactured to National Formulary specifications, which we refer to as P188-NF. Early clinical studies of P188, performed prior to 1996, were conducted using P188-NF. Initial studies in patients with sickle cell disease (SCD) and AMI were promising and demonstrated important clinical benefits [28, 30]. However, in larger studies in patients with AMI, P188-NF was associated with dose-dependent, moderate to moderately severe elevations in serum creatinine levels. These changes were most obvious in subjects aged 65 years and greater and in those with elevated creatinine levels at baseline [31]. Development of P188-NF was discontinued following this finding. P188 is chemically synthesized in two steps, first by building the (poly)oxypropylene core, and second by addition of poly(oxyethylene) to the terminal ends of the polyoxypropylene core. Because of variation in the rates of polymerization during both steps, $\mathrm{P} 188-\mathrm{NF}$ consists of a bell-shaped distribution of polymer species, which vary primarily in overall chain length. In addition, various low molecular weight (LMW) substances (e.g., glycols and truncated polymers), formed by incomplete polymerization, and dimerized polymers typically are present. Characterization of P188-NF using gel permeation chromatography (GPC) identifies a main peak of P188 with "shoulder" peaks on both sides representing the unintended LMW and high molecular weight (HMW) related substances. We hypothesized that the LMW substances present in P188-NF were causal and/or contributed disproportionately to the renal dysfunction observed with this agent. We further hypothesized that removal of these substances would result in an agent with substantially less effect on renal function, without otherwise affecting its activity. Here, we show the nature of the renal injury associated with P188-NF and demonstrate that a "purified" and less polydisperse form of $\mathrm{P} 188$, which we refer to as $\mathrm{P} 188-\mathrm{P}^{1}$ throughout this publication, has a significantly lesser effect on renal function in a remnantkidney animal model and is well tolerated in clinical studies. The role of the unpurified, excipient-grade material (P188$\mathrm{NF}$ ), and its impact on the results obtained in earlier clinical trials, is also discussed.

\section{Materials and Methods}

\subsection{Purification of P188-NF}

A supercritical fluid extraction process was used to prepare P188-P. Commercial-grade poloxamer 188 (P188-NF; BASF Corporation) was supported on a polystyrene divinyl

\footnotetext{
1 The nomenclature associated with P188-P has changed over the years. It is currently referred to as MST-188, but previously has been called CRL 5861 and FLOCOR.
} 
benzene solid matrix (XAD-4; Supelco) in a high-pressure stainless steel vessel and extracted with carbon dioxide and modifying co-solvents (approximately 4 mole \%) at $6,000 \mathrm{psi}$ and $40{ }^{\circ} \mathrm{C}$. The extraction proceeded until approximately $80 \%$ of the total LMW material had been removed as analyzed by GPC. When the extraction was complete, methanol was used to elute the purified poloxamer 188 (P188-P) from the matrix. The waste stream was also collected and evaporated. The yield of P188-P was typically $75-80 \%$ of the loaded P188-NF. Gas chromatography and nuclear magnetic resonance were used to analyze the levels of unsaturation groups and LMW glycol species in P188-NF and P188-P, respectively. A similar supercritical fluid extraction process modified to comply with Current Good Manufacturing Practice (cGMP) was used to prepare P188-P for clinical studies. Clinical-grade P188-P was sterilized via a terminal autoclaving process, which had been pre-validated by measuring the recovery of reference material post-treatment.

\subsection{Test Agents}

For all studies, both P188-NF and P188-P were formulated as a $15 \%$ sterile aqueous solution of the appropriate agent in a vehicle containing sodium chloride $3.08 \mathrm{mg} / \mathrm{mL}$, sodium citrate $2.38 \mathrm{mg} / \mathrm{mL}$, and citric acid $0.366 \mathrm{mg} / \mathrm{mL}$. Control infusions were conducted using only the vehicle.

\subsection{Remnant-Kidney Animal Model}

Female Sprague-Dawley rats, aged 6-8 weeks, were subjected to 5/6 nephrectomy, as described by Anderson et al. [32-34], and were allowed to recover for at least 15 days. Remnant-kidney rats with stable renal function were stratified by renal function and randomized to treatment groups. The treatment-group animals were anesthetized (using an intraperitoneal injection of ketamine 15-20 mg/ $\mathrm{kg}$ ) and intravenously infused for $6 \mathrm{~h}$ via the tail vein with supra-pharmacologic dosages of P188-P or P188-NF, using a syringe infusion pump (Harvard Apparatus). Three control animals similarly received a $6 \mathrm{~h}$ infusion of vehicle only. The infusion rates were $0.3-0.4,0.6-0.8$, and $1.2-1.6 \mathrm{~mL} / \mathrm{h}$ in the 250,500 , and $1,000 \mathrm{mg} / \mathrm{kg}$ dose groups, respectively. The number of animals in each treatment group was as follows: 4, 6, and 25 animals received P188-P in the 250,500 , and $1,000 \mathrm{mg} / \mathrm{kg}$ dose groups, respectively, and 3,10 , and 30 animals received $\mathrm{P} 188-\mathrm{NF}$ in the 250,500 , and $1,000 \mathrm{mg} / \mathrm{kg}$ dose groups, respectively. Serum samples for creatinine testing were collected at $3 \mathrm{~h}$ (i.e., during the infusion), at $6 \mathrm{~h}$ (i.e., at the end of the infusion) and at 24 and $48 \mathrm{~h}$ following the end of the infusion (post-infusion). Creatinine levels were measured according to Heinegård and Tiderström [35]. At 48 h post-infusion, the animals were humanely euthanized and their kidneys were harvested and processed for histopathologic examination.

The reversibility of treatment-induced changes was examined in a separate group of remnant-kidney rats following a 6-h infusion of either P188-P $(1,000 \mathrm{mg} / \mathrm{kg} / \mathrm{h})$ or P188-NF $(1,000 \mathrm{mg} / \mathrm{kg} / \mathrm{h})$, with histopathology examination conducted at 24,48 , and $144 \mathrm{~h}$ post-infusion.

\subsection{Histopathology}

Tissue sections of the remnant kidneys were prepared according to standard techniques and stained with hematoxylin and eosin (H\&E) and with periodic acid-Schiff (PAS). Light microscopic examinations were performed by a renal pathologist blinded to treatment. Tissues were also examined by transmission electron microscopy for treatment-induced ultrastructural effects.

\subsection{Clinical Studies}

Two clinical studies were conducted to evaluate the effects of P188-P on safety and renal function in patients with SCD. Both studies involved test agent administration consisting of a loading dose administered intravenously over $1 \mathrm{~h}$, followed by a maintenance dose administered over either 23 or $47 \mathrm{~h}$. In one study (study C97-1248), 126 subjects were treated with a total dose of $1.5 \mathrm{~g} / \mathrm{kg}$. In the other study (study C97-1243), 42 subjects were randomized in an escalating manner to receive total doses ranging from 1.1 to $2.9 \mathrm{~g} / \mathrm{kg}$. Urinary and plasma-based renal function biomarkers were evaluated at baseline and throughout the C97-1243 trial, and plasma creatinine was assessed in both trials.

All studies were conducted according to Good Clinical Practice (GCP)/International Conference on Harmonisation (ICH) standards on consented subjects, and specimens were collected accordingly.

\section{Results}

\subsection{Purification of P188-NF}

Representative GPC profiles of P188-NF and P188-P are shown in Fig. 2. The predominant peak (between 14 and 15 minutes) identifies the desired molecular species. P188-NF typically contains about $5 \%$ (by weight) LMW substances $(<5,500 \mathrm{Da})$ [see Fig. 2a; dashed-line circle eluting after $15 \mathrm{~min}$ ], which were targeted for removal. These LMW substances are greatly reduced or absent in P188-P [see Fig. 2b, dashed-line circle]. HMW contaminants (approximately 16,000 Da) elute at between 13 and $14 \mathrm{~min}$. 

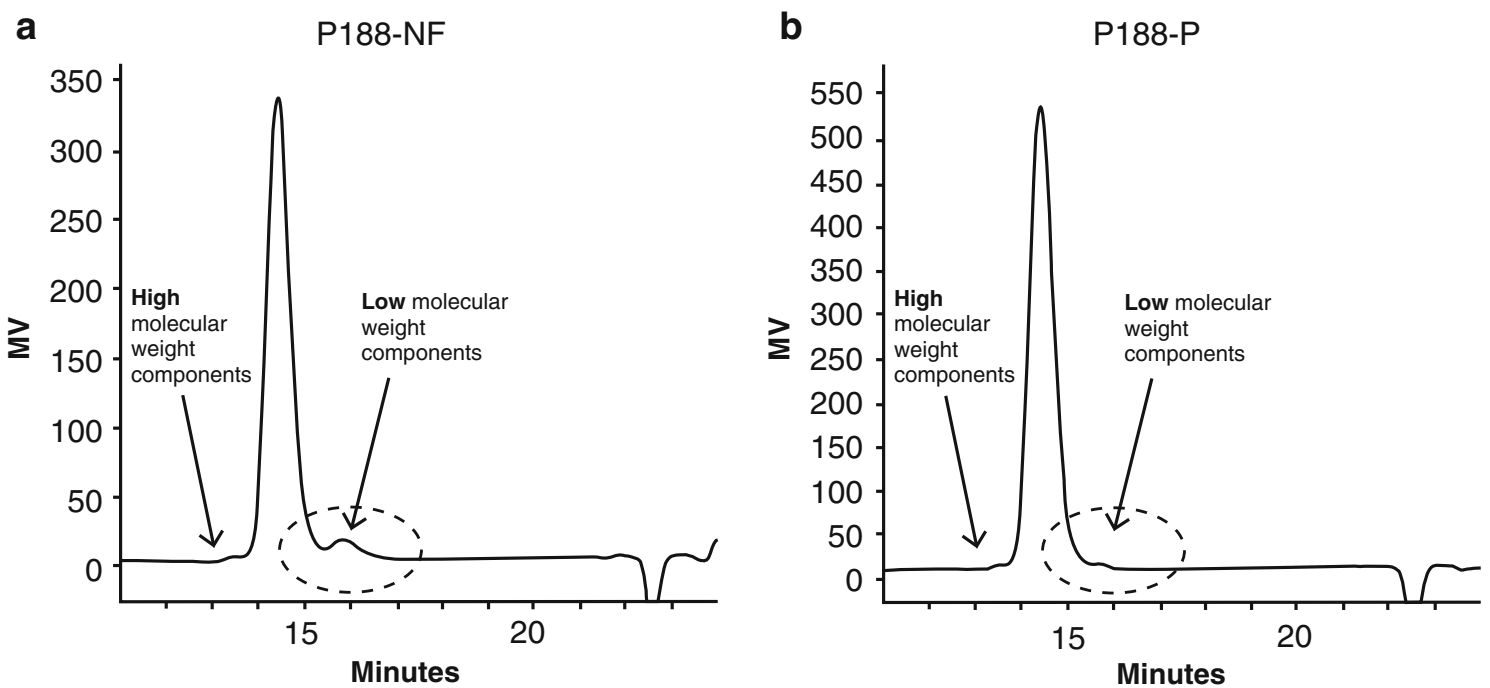

Fig. 2 Gel permeation chromatography (GPC) profiles of $\boldsymbol{a}$ excipient-grade poloxamer 188 (P188-NF) and $\boldsymbol{b}$ purified poloxamer 188 (P188-P)

\subsection{Remnant-Kidney Animal Model}

\subsubsection{Histology and Ultrastructure}

Histologic evaluation of H\&E-stained sections of remnant kidneys in rats infused with P188-NF demonstrated dose-related diffuse cytoplasmic vacuolization in the epithelial cells of the proximal convoluted tubule (PCT) (Fig. 3). The vacuolization was restricted to the PCT, as no changes were observed in the distal convoluted tubule (DCT). The cytoplasmic vacuoles contained PAS-positive droplets, suggesting that they harbored reabsorbed protein. PAS staining also revealed that the epithelial brush borders were normal in appearance and the basement membranes were intact. A similar pattern of doserelated vacuolization was observed with P188-P, although to a lesser extent. No other abnormalities related to inflammation or necrosis were observed with either treatment.

Electron microscopy revealed similar ultrastructural findings to those seen with histologic evaluation. Remnant kidneys treated with either P188-NF or P188-P showed numerous cytoplasmic (apparently membranebound) vacuoles containing electron-dense aggregates (presumably protein). The vacuolization was again limited to the PCT, with none being detected in either the DCT or the collecting ducts. There were no transition forms to suggest that the vacuoles had been derived from degenerating mitochondria. The epithelial brush borders and basement membranes were intact and normal in appearance, and there was no evidence of necrosis or irreversible injury.

\subsection{Effect on Creatinine}

Treatment with P188-NF and P188-P resulted in dosedependent increases in serum creatinine at $24 \mathrm{~h}$ post-infusion. However, the elevations in creatinine were generally lower among animals treated with P188-P. At the highest dose level (i.e., $1,000 \mathrm{mg} / \mathrm{kg} / \mathrm{h}$ ), the mean creatinine level in animals treated with $\mathrm{P} 188-\mathrm{NF}$ at $24 \mathrm{~h}$ post-infusion was $2.48 \mathrm{mg} / \mathrm{dL}$, representing an increase of $1.41 \mathrm{mg} / \mathrm{dL}$ from baseline (Table 1). In comparison, the same parameter in animals treated with P188-P was $1.73 \mathrm{mg} / \mathrm{dL}$, representing an increase of $0.86 \mathrm{mg} / \mathrm{dL}$ from baseline. Both the 24-h creatinine levels and the changes in creatinine levels from baseline to $24 \mathrm{~h}$ differed significantly between P188-P and P188-NF ( $p=0.0005$ and $p=0.005$, respectively).

Table 2 shows creatinine clearance values following treatment with either P188-P or P188-NF. Creatinine clearance was higher in animals treated with $\mathrm{P} 188-\mathrm{P}$ at doses of 250 and $500 \mathrm{mg} / \mathrm{kg} / \mathrm{h}$ than in animals treated with $\mathrm{P} 188-\mathrm{NF}$ at similar doses. At $1,000 \mathrm{mg} / \mathrm{kg} / \mathrm{h}$, creatinine clearance was high in both groups, with no difference between treatments.

Survival following supra-pharmacologic dosing $(1,000 \mathrm{mg} / \mathrm{kg} / \mathrm{h})$ was higher at both 24 and $48 \mathrm{~h}$ postinfusion in animals treated with P188-P than in those treated with P188-NF (Fig. 4). Survival at $24 \mathrm{~h}$ was $92 \%$ $(23 / 25)$ in animals treated with P188-P, compared with $64 \%(16 / 25)$ in animals treated with P188-NF $(p=0.04)$. Survival at $48 \mathrm{~h}$ was $70 \%(21 / 30)$ and $50 \%(15 / 30)$ for $\mathrm{P} 188-\mathrm{P}$ and P188-NF, respectively $(p=0.3)$. Administration of equivalent amounts of the LMW substances isolated during the supercritical fluid extraction procedure resulted 


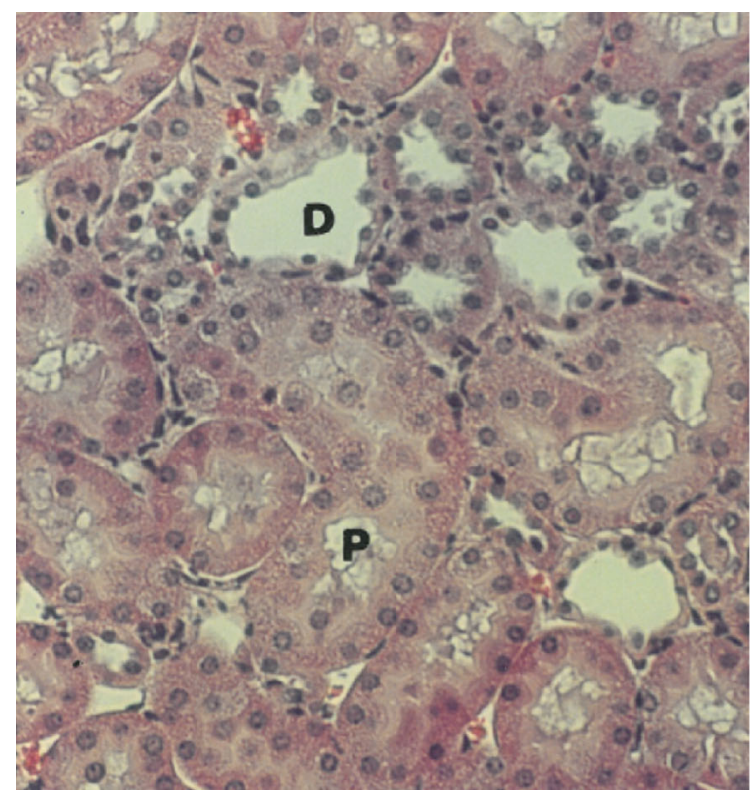

Fig. 3 Hematoxylin and eosin (H\&E)-stained sections: the left panel represents normal-appearing cells following a saline infusion; the right panel represents the cytoplasmic vacuolization of the proximal convoluted tubule (PCT), with sparring of the distal convoluted tubule

Table 1 Serum creatinine for remnant kidney animals treated with P188-P or P188-NF

\begin{tabular}{llll}
\hline $\begin{array}{l}\text { Treatment and } \\
\text { dose }(\mathrm{mg} / \mathrm{kg} / \mathrm{h})\end{array}$ & $\begin{array}{l}\text { Baseline } \\
(\mathrm{mg} / \mathrm{dL})\end{array}$ & $\begin{array}{l}\text { 24 h post- } \\
\text { infusion } \\
(\mathrm{mg} / \mathrm{dL})\end{array}$ & $\begin{array}{l}\text { Change from } \\
\text { baseline }(24 \mathrm{~h}) \\
(\mathrm{mg} / \mathrm{dL})\end{array}$ \\
\hline $\mathrm{P} 188-\mathrm{NF}$ & & & \\
250 & $1.07 \pm 0.2$ & $1.59 \pm 0.7$ & $+0.52 \pm 0.5$ \\
500 & $1.23 \pm 0.3$ & $1.85 \pm 0.6$ & $+0.62 \pm 0.5$ \\
1,000 & $1.07 \pm 0.3$ & $2.48 \pm 0.6^{*}$ & $+1.41 \pm 0.6^{* *}$ \\
$\mathrm{P} 188-\mathrm{P}$ & & & \\
250 & $1.5 \pm 0.5$ & $2.15 \pm 0.5$ & $+0.65 \pm 0.7$ \\
500 & $0.93 \pm 0.2$ & $1.5 \pm 0.2$ & $+0.57 \pm 0.3$ \\
1,000 & $0.87 \pm 0.3$ & $1.73 \pm 0.7^{*}$ & $+0.86 \pm 0.7 * *$ \\
\hline
\end{tabular}

$* p=0.0005, * * p=0.005$ for the comparison between P188-NF and P188-P

in markedly reduced survival at $24 \mathrm{~h}$ (less than $10 \%$; data not shown). Doses less than $1,000 \mathrm{mg} / \mathrm{kg} / \mathrm{h}$ had negligible effects on survival: only one of six rats died after infusion with $500 \mathrm{mg} / \mathrm{kg} / \mathrm{h}$, and there was $100 \%$ survival in the $250 \mathrm{mg} / \mathrm{kg} / \mathrm{h}$ group.

The reversibility of the renal effects of P188-P and P188-NF was also studied at $24,48,96$, and $144 \mathrm{~h}$ postinfusion following a dose of $1,000 \mathrm{mg} / \mathrm{kg} / \mathrm{h}$ for $6 \mathrm{~h}$. At $24 \mathrm{~h}$, widespread vacuolization of PCT was observed with both P188-P and P188-NF, with no major differences in the degree of vacuolization between the two compounds. However, by $48 \mathrm{~h}$, widespread vacuolization was still present with P188-NF, while much less vacuolization was

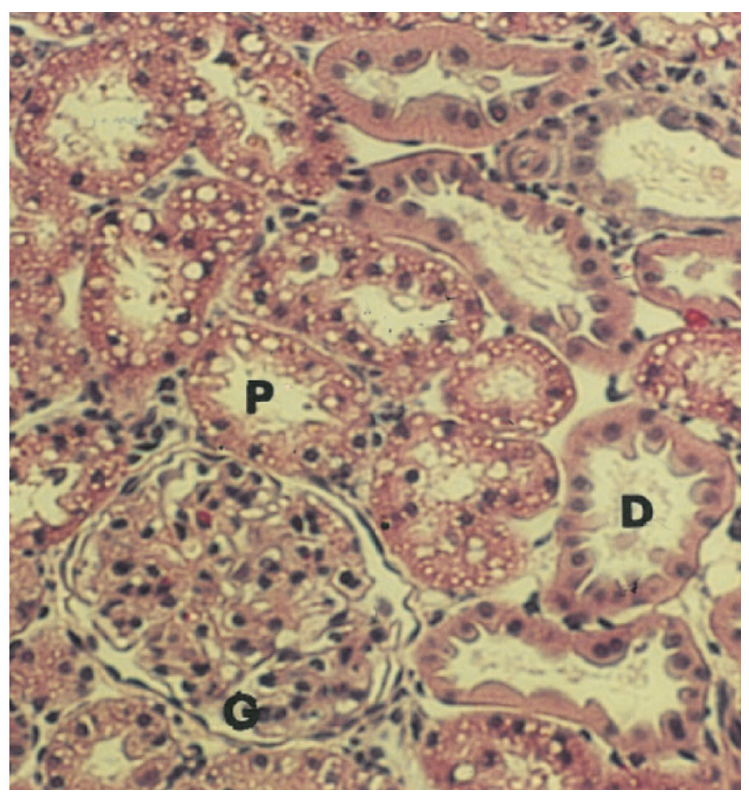

(DCT) observed more prominently with excipient-grade poloxamer 188 (P188-NF). Proximal convoluted tubules (P), distal tubules (D) and glomeruli $(G)$ are indicated (magnification, $\times 400$ )

Table 2 Serum creatinine clearance in remnant-kidney animals treated with excipient-grade poloxamer 188 (P188-NF) or purified poloxamer 188 (P188-P)

\begin{tabular}{ll}
\hline $\begin{array}{l}\text { Treatment and } \\
\text { dose }(\mathrm{mg} / \mathrm{kg} / \mathrm{h})\end{array}$ & $\begin{array}{l}\text { Creatinine clearance at end of infusion } \\
(\mu \mathrm{l} / \mathrm{min} / 100 \mathrm{~g} ; \text { mean } \pm \text { standard deviation })\end{array}$ \\
\hline $\begin{array}{l}\text { P188-NF } \\
250\end{array}$ & $63 \pm 40$ \\
500 & $86 \pm 113$ \\
1,000 & $246 \pm 141$ \\
P188-P & \\
250 & $168 \pm 116$ \\
500 & $164 \pm 116$ \\
1,000 & $225 \pm 217$ \\
\hline
\end{tabular}

observed in animals infused with P188-P. At 96 h, minimal vacuolization was observed with P188-P, while slightly fewer but larger vacuoles were present in the P188-NFtreated animals. At $144 \mathrm{~h}$, vacuolization was no longer observed and PCT appeared normal in P188-P-treated animals, while some degree of vacuolization was still observed in P188-NF-treated animals.

\subsubsection{Clinical Studies}

To date, there have been five clinical studies investigating P188-P in healthy volunteers or in patients with SCD. Various dosing regimens, involving both intravenous loading and maintenance dosing, have been evaluated. 
Study C97-1248 evaluated use of P188-P in SCD patients with acute vaso-occlusive crisis (VOC). Two hundred fifty-five (255) patients with SCD-VOC were randomized to receive standard of care (hydration and analgesics for pain) and either P188-P (test) or volumematched saline (control). The subjects had a serum creatinine level $\leq 1.0 \mathrm{mg} / \mathrm{dL}$. Patients randomized to the test arm received P188-P intravenously at a loading dose of $100 \mathrm{mg} / \mathrm{kg}$ over $1 \mathrm{~h}$, followed by a maintenance dose of $30 \mathrm{mg} / \mathrm{kg} / \mathrm{h}$ over $47 \mathrm{~h}$, corresponding to a total dose of $1.5 \mathrm{~g} / \mathrm{kg}$. Patients randomized to the control arm received a saline solution delivered at a volume and duration identical to those used for the active drug. Serum was periodically collected for creatinine testing both during the study and in the follow-up period (i.e., $>48 \mathrm{~h}$ ). The mean serum creatinine level and standard deviation for all study subjects over time are shown in Fig. 5. The mean values for serum creatinine were not clinically or statistically different between subjects treated with placebo and those treated with P188-P, and neither group showed significant changes from baseline through follow-up.

A summary table for serum creatinine elevations in subjects enrolled in study C97-1248, stratified according to toxicity grade, is shown in Table 3 . The National Cancer Institute Common Toxicity Criteria, Version 1, were used in this analysis [36]. Any instances of elevated creatinine values measured post-infusion were included in the table. Overall, the incidence of elevated creatinine levels for all grades was similar in both treatment groups.

Study C97-1243 was an open-label trial evaluating the safety of varying doses of P188-P in pediatric and adult SCD subjects experiencing acute chest syndrome. Five different groups were intravenously administered a common loading dose of $200 \mathrm{mg} / \mathrm{kg}$ for $1 \mathrm{~h}$, followed by maintenance doses for $23 \mathrm{~h}$. The maintenance dose was different in each group and ranged from 20 to $120 \mathrm{mg} / \mathrm{kg} / \mathrm{h}$.

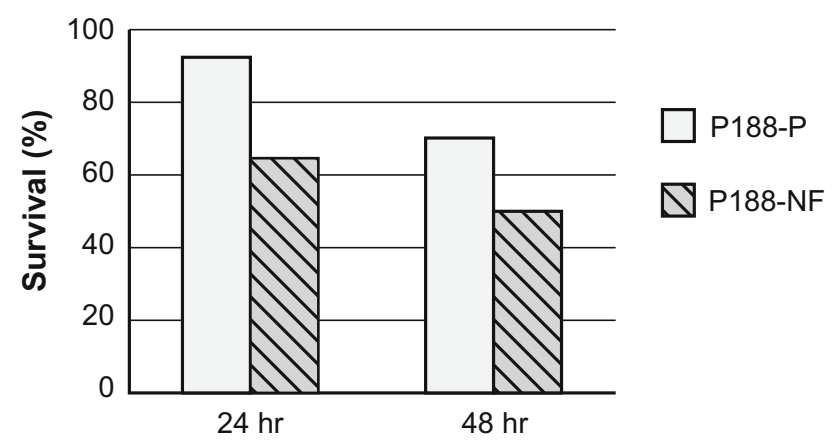

Fig. 4 Survival following supra-pharmacologic dosing of excipientgrade poloxamer 188 (P188-NF) and purified poloxamer 188 (P188$\mathrm{P})$ in remnant-kidney animals $(n=25$ animals/group in each 24-h group; $n=30$ animals/group in each 48-h group). Survival $(\%)=$ (number of animals alive at indicated time point/number of animals at $t=0) * 100$
The total dose ranged from a low of $1.1 \mathrm{~g} / \mathrm{kg}$ to a high of $2.9 \mathrm{~g} / \mathrm{kg}$. For comparison, the lower doses in study C971243 overlapped with doses of P188-NF that yielded unacceptable renal toxicity in AMI patients, while the higher doses exceeded the maximum doses of P188-NF by almost 2-fold. Study C97-1243 also included renal function studies to assess the effect of P188-P on the nephron. These assessments were performed on specimens collected at baseline and upon completion of the P188-P infusion, as well as on specimens collected 1 day, 2 days, 3 days, 5-10 days, and 28-35 days after the infusion. The tests that were utilized, and the renal functions they evaluate (as indicated in parentheses) are as follows: serum creatinine (glomerular filtration), creatinine clearance (glomerular filtration), $\quad \beta$ - $N$-acetylglucosaminidase levels (tubular injury), retinol binding protein levels (protein absorption pathways), albumin (integrity of glomerulus), immunoglobulin $\mathrm{G}$ (IgG) excretion (glomerulus permeability), and urine osmolarity (distal tubular transport).

Figure 6 presents the mean serum creatinine levels in the dose groups in study C97-1243 during and after a 24-h intravenous infusion of P188-P. The mean baseline creatinine levels were within normal ranges for all dose groups $(<136 \mu \mathrm{mol} / \mathrm{L}[<1.5 \mathrm{mg} / \mathrm{dL}]$ in men and $<120 \mu \mathrm{mol} / \mathrm{L}$ $[<1.4 \mathrm{mg} / \mathrm{dL}]$ in women) [34]. Following treatment, the mean values generally remained within the normal range and there were no clear dose-related changes. In one group (receiving $100 \mathrm{mg} / \mathrm{kg} / \mathrm{h}$ ), the data were skewed by a single subject who developed septic shock with kidney failure, which was determined by the investigator to be unrelated to the treatment. Similarly, a transient rise in serum creatinine on day 2 was observed in the $120 \mathrm{mg} / \mathrm{kg} / \mathrm{h}$ group. This also was unlikely to be indicative of a treatment-related effect, since it was driven by a value from a single individual whose baseline value was $1.2 \mathrm{mg} / \mathrm{dL}$ and where the day 2

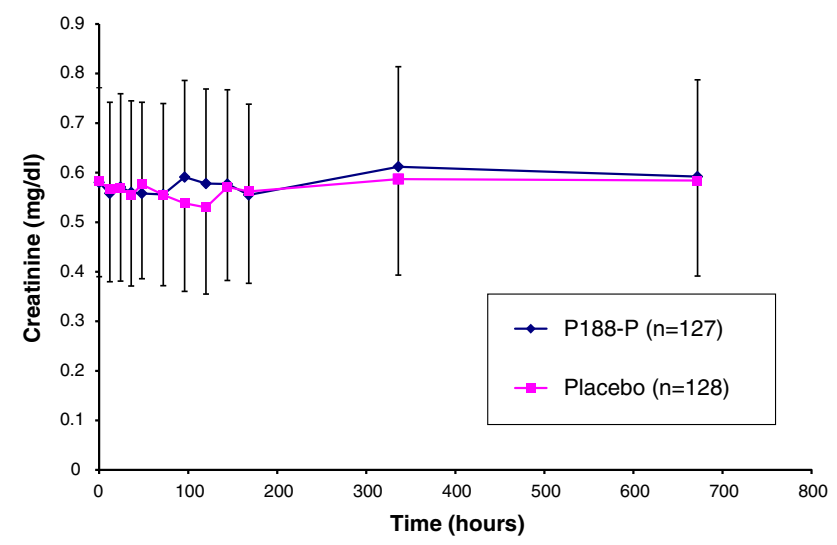

Fig. 5 Changes in serum creatinine levels following administration of purified poloxamer 188 (P188-P) or placebo to patients with sickle cell disease (SCD). Each bar represents the mean \pm standard deviation for measurements conducted in the indicated group 
Table 3 Numbers of patients with elevated creatinine levels, stratified by toxicity grade and age, in study C97-1248

\begin{tabular}{|c|c|c|c|c|}
\hline \multirow[t]{3}{*}{ Toxicity grade ${ }^{\mathrm{a}}$} & \multicolumn{4}{|c|}{ Subjects with elevated creatinine levels $(n)$} \\
\hline & \multicolumn{2}{|c|}{ Adults (aged $\geq 16$ years; $n=176$ ) } & \multicolumn{2}{|c|}{ Children (aged $<16$ years; $n=73$ ) } \\
\hline & P188-P & Placebo & P188-P & Placebo \\
\hline 1 & 46 & 49 & 18 & 14 \\
\hline 2 & 12 & 9 & 5 & 3 \\
\hline 3 & 1 & 0 & 0 & 1 \\
\hline 4 & 0 & 0 & 0 & 0 \\
\hline
\end{tabular}

P188- $P$ purified poloxamer 188

a Toxicity grades according to the National Cancer Institute Common Toxicity Criteria, Version 1 [36]

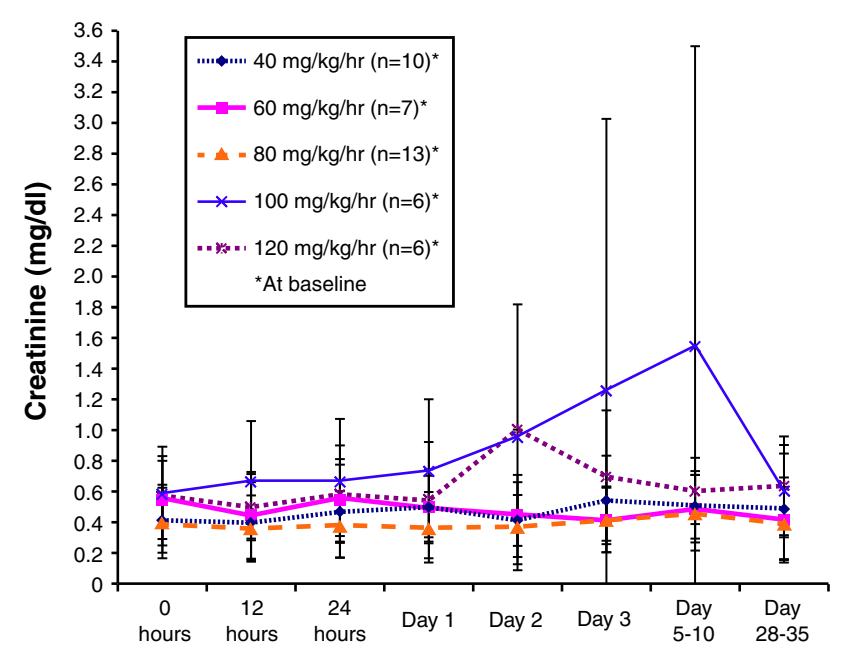

Fig. 6 Serum creatinine levels in patients treated with purified poloxamer 188 (P188-P). Each bar represents the mean \pm standard deviation for measurements conducted in the indicated group

value actually represented a decrease from baseline. Excluding these outliers, the data support that treatment with P188-P does not result in differences in mean serum creatinine across the dose range studied.

Figure 7 presents mean creatinine clearance values for the dose groups in study C97-1243 during and after a 24-h intravenous infusion of P188-P. Consistent with the serum creatinine results, the serum creatinine clearance data does not identify any dose-related changes or clinically significant effects across time. A transient change in creatinine clearance at day 2 was observed in the $120 \mathrm{mg} / \mathrm{kg} / \mathrm{h}$ group; however, this likely was influenced by the results from a single subject, as previously noted.

Figures 8 and 9 present data obtained from tests performed in study C97-1243 during and after a 24-h intravenous infusion of P188-P in the dose groups that were studied. Figure 8 presents results for urinary $\beta$ - $N$-acetylglucosaminidase, and Fig. 9 presents results for retinol binding protein levels. Collectively, these results and those from testing urinary albumin, urinary IgE excretion, and urine

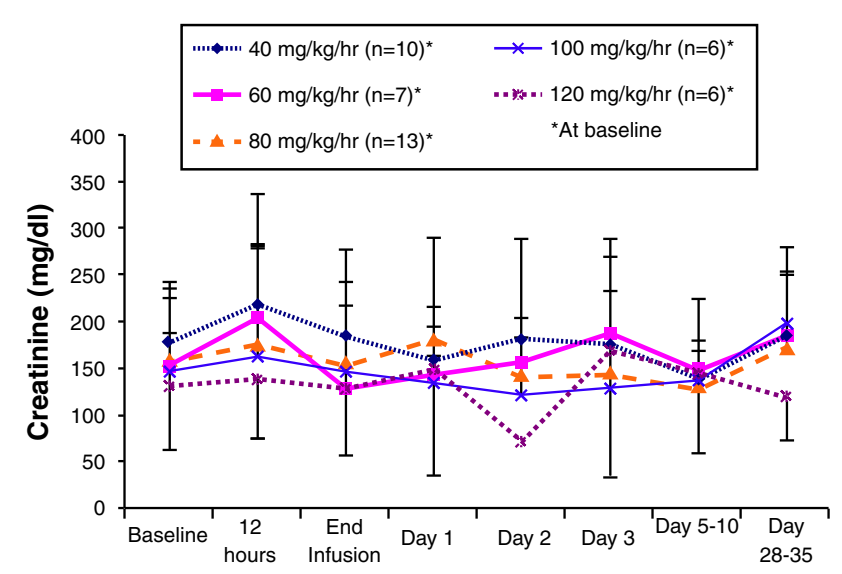

Fig. 7 Serum creatinine clearance in patients treated with purified poloxamer 188 (P188-P). Each bar represents the mean \pm standard deviation for measurements conducted in the indicated group

osmolarity (data not shown) did not reveal any dose-related patterns or other changes suggestive of renal dysfunction across the range of P188-P doses that were studied.

\section{Discussion}

We have prepared and studied a more homogeneous form of P188 by removing certain LMW substances found in commercially available, excipient-grade P188 and comparing the purified form (P188-P) with the unpurified material (P188-NF). Since elevated creatinine was the dose-limiting toxicity identified in prior clinical trials of P188-NF, we compared the two materials using 5/6 nephrectomized rats, where $5 / 6$ of kidney function is ablated and the residual kidney is highly sensitive to the effects of potential renal toxicants [32-34].

\subsection{Renal Changes Following Exposure to P188 are Consistent with Osmotic Nephrosis}

Histologic evaluation of stained kidney sections from nephrectomized rats infused with P188-P or P188-NF show 
hydropic swelling and vacuolization within the epithelial cells of the nephron's PCTs. The effect is dose dependent, with vacuolization restricted to the PCT. The presence of PAS-positive droplets inside the cytoplasmic vacuoles demonstrated that the vacuoles contained reabsorbed protein. However, even at the highest dose that was studied $(1,000 \mathrm{mg} / \mathrm{kg} / \mathrm{h})$, there was no histopathologic evidence of tubule necrosis. Electron microscopy confirmed that the brush border was anatomically intact and that the mitochondria appeared normal, showing no transition forms, amplitude swelling, or formation of matrical granules.

Vacuolation of the renal tubule epithelium, like that induced by P188, has been observed in Sprague-Dawley rats during toxicologic evaluation of polyethylene glycol (PEG)-linked proteins. Rather severe lesions were present when lower molecular weight PEG-linked proteins were tested, while minimal, if any, were seen with PEG-linked proteins $>70 \mathrm{kD}$, suggesting that protein with attached PEG was reabsorbed by the proximal tubules. The observed vacuolation that accompanied the response was thought to result from fluid distension within lysosomes due to the hygroscopic nature of PEG [37]. Unconjugated PEG, of masses similar to that of P188, preferentially accumulate in the renal epithelium [38]. Others have discussed that lysosomal dysfunction, presenting as intracellular vacuolation, is a common feature of biopersistent materials, such as PEG [39].

The hydropic swelling and vacuolization induced by $\mathrm{P} 188$ also resembles a type of vacuolar nephrosis deemed osmotic or hypokalemic nephrosis. It is considered a reversible condition, often observed in patients after infusion with hypertonic solutions of sucrose, mannitol, or dextran. In a recent clinical study, infusion of immunoglobulin preparations containing sucrose as a stabilizing agent resulted in a fully reversible form of acute renal failure, with histologic changes characterized by vacuolization and swelling of renal proximal tubule cells. The authors suggested that the risk of

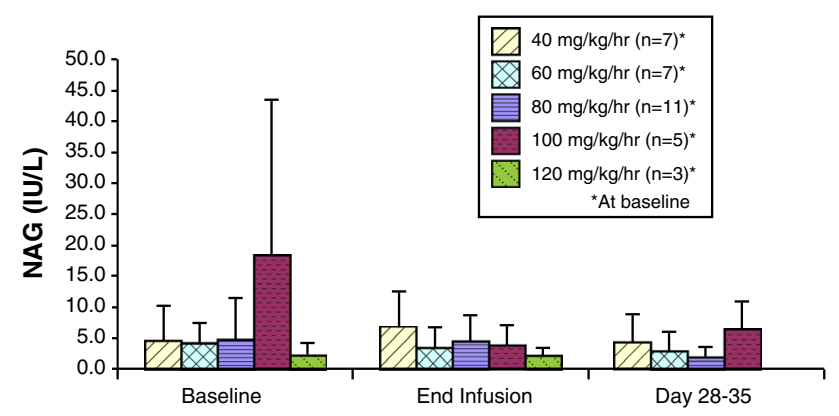

Fig. 8 Urinary $\beta$ - $N$-acetylglucosaminidase (NAG) levels in patients treated with purified poloxamer 188 (P188-P). Each bar represents the mean \pm standard deviation for measurements conducted in the indicated group

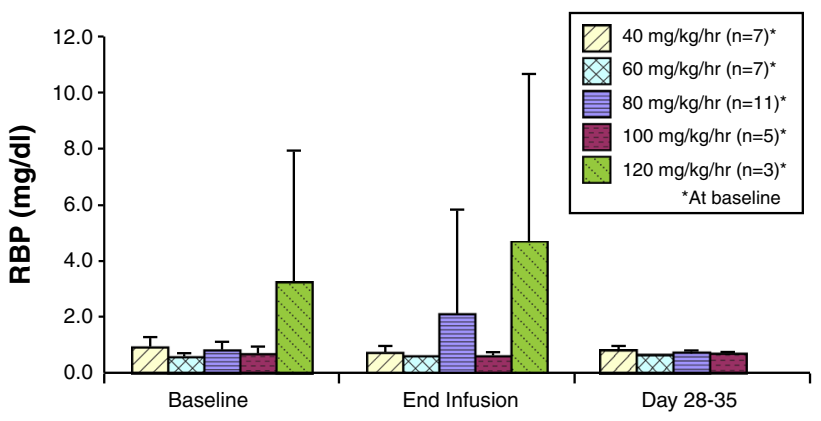

Fig. 9 Retinol binding protein levels in patients treated with purified poloxamer 188 (P188-P). Each bar represents the mean \pm standard deviation for measurements conducted in the indicated group

such injury could be minimized by dilution of the immunoglobulin preparation and by slowing the infusion rate [40]. Hypokalemic nephrosis, a condition commonly seen in cases of chronic diarrhea, is due to potassium depletion. This condition, which is caused by disturbance in the osmotic and electrolyte balance within the tubule cells, also is fully reversible.

\subsection{P188-P is Less Injurious, and Changes are More Readily Reversible}

Both P188-NF and P188-P induced dose-dependent increases in serum creatinine levels. However, at high doses, the elevation in serum creatinine levels induced by P188-NF was significantly greater than what was observed with P188-P. Mortality at $24 \mathrm{~h}$ was significantly higher in animals administered P188-NF than in animals receiving P188-P (30.77 versus $11.48 \% ; p<0.01$ ). Mortality at $48 \mathrm{~h}$ was also reduced with P188-P, though the difference was not statistically significant.

It is important to point out that, when administered to rats with intact renal function at the dosages used in this study, P188-NF is well tolerated and changes in creatinine are not observed. This suggests that the mortality observed in the 5/6-remnant rats is due to their increased sensitivity to renal toxicants resulting from loss of renal function. Likewise, the improved survival with P188-P suggests that purified P188 is likely to be better tolerated when renal function is compromised.

We also examined the reversibility of vacuolar lesions following infusion of P188-P or P188-NF in the nephrectomized rat. Infusion with P188-P at supra-pharmacologic dosing produced coarse vacuolization, which had completely reversed by $96-144 \mathrm{~h}$ after infusion. In contrast, the vacuolization produced by P188-NF involved a slower rate of recovery, since coarse vacuolization was still present $144 \mathrm{~h}$ following infusion.

We conclude from these observations in nephrectomized rats that the effect on renal function observed with 
P188-NF is markedly attenuated with P188-P, suggesting that LMW substances present in P188-NF contribute substantially to its effect on renal function. Further, the changes do not involve inflammation or necrosis, resemble osmotic nephrosis, and are fully reversible. It most likely represents an exaggeration of the normal vacuolar reabsorption pathway.

\subsection{The Renal Dysfunction Observed in Clinical Studies of P188-NF is not Observed in Clinical Studies of P188-P}

Following discussions with the US Food and Drug Administration regarding the remnant-kidney animal model and the results of clinical studies in healthy volunteers, study C97-1248 was initiated. Patient serum creatinine levels were monitored for 28 days after a 48-h infusion with P188-P or placebo. At all evaluation time points, there was no difference in mean serum creatinine levels between treatment arms. Changes in serum creatinine were also graded according to the National Cancer Institute Common Toxicity Criteria. Overall, the incidence of elevated creatinine for all grades was similar in both treatment groups. Importantly, there was a single instance of grade 3 creatinine elevation in each treatment arm and no instances of grade 4 changes.

Study C97-1243 evaluated the safety of administering increasing doses of P188-P to pediatric and adult SCD patients experiencing acute chest syndrome. Subjects were administered a 1-h loading dose followed by a maintenance dose, which was administered over $23 \mathrm{~h}$. The total dose of P188-P that was administered ranged from a low of $1.1 \mathrm{~g} /$ $\mathrm{kg}$ to a high of $2.9 \mathrm{~g} / \mathrm{kg}$. Across all dose groups, there were no clinically or statistically significant differences in mean serum creatinine levels or mean creatinine clearance from baseline or between groups. Similarly, no changes from baseline or between dose groups was observed in a variety of renal function tests, including urinary $\beta$ - $N$-acetylglucosaminidase, urinary retinol binding protein, urine albumin levels, IgG excretion, and urine osmolarity.

It is worthwhile to compare the renal toxicity observed in patients receiving $\mathrm{P} 188-\mathrm{NF}$ with the renal toxicity observed in patients receiving P188-P. In AMI patients, P188-NF resulted in measurable dose-dependent increases in serum creatinine across a dose range from about 300 to about $1,800 \mathrm{mg} / \mathrm{kg}$. In the higher-dose groups, the mean change from baseline was between 0.5 and $0.6 \mathrm{mg} / \mathrm{dL}$. In contrast, in SCD patients, P188-P resulted in no dosedependent changes in mean creatinine or changes from baseline at significantly higher doses (between 1.1 and $2.9 \mathrm{~g} / \mathrm{kg}$ ). While the two study populations are not directly comparable, in light of the benefits associated with P188-P in nonclinical studies, it is reasonable to conclude that the improved renal outcomes observed with P188-P are derived from the selective removal of LMW substances present in P188-NF.

Finally, it is worth commenting on the role of the LMW substances in mediating adverse renal effects. It has been reported by Schmolka and others that the toxicity of poloxamers increases with decreasing molecular weight and an increasing hydrophobic/hydrophilic ratio [41]. This is because as poloxamers become smaller and more hydrophobic, they likely behave more like detergents, such as Triton X-100, which are known to be injurious to cells through disruption of cell membranes. In contrast, larger, more relatively hydrophilic poloxamer molecules, such as the species contained in the main peak of poloxamer 188 , have the opposite effect and act as membrane sealants [42]. Accordingly, we believe that certain LMW components of the poloxamer 188 polymeric distribution may act more like Triton detergents to initiate or propagate membrane injury and, through this mechanism, may contribute to adverse renal effects.

\section{Conclusions}

1. The renal dysfunction associated with P188-NF (commercially available, excipient-grade material) is dose dependent and is characterized histologically by coarse vacuolization in the proximal tubule epithelium, with no evidence of necrosis or irreversible cellular damage.

2. The renal dysfunction observed with P188-NF is associated with LMW substances present in P188NF. These substances can be reduced via supercritical fluid extraction.

3. Compared with P188-NF, P188-P with reduced LMW substances was better tolerated in a remnant-kidney animal model. In this model, P188-P resulted in less pronounced vacuolization, with more rapid recovery, less effect on serum creatinine, and significantly improved tolerability. Any effects of P188-P on renal function are predicted to be fully reversible.

4. In studies investigating P188-P, the pattern of dosedependent changes in serum creatinine previously observed with P188-NF was not observed, even with significantly higher levels of exposure. This suggests that the benefits of P188-P observed in animal studies translate to humans.

Acknowledgments The authors wish to acknowledge the technical assistance of Abdul Al-Khalidi, Himanshu Shah, Pingping Wang, and Hal Lee in the preparation and characterization of purified poloxamer; Carlos Rivera-Marrero and Medea Mshvildadze for assistance with the nephrectomized rat studies; Melvin Schwartz for assistance with 
the histopathologic studies, and Doug McKenzie for assistance in the preparation of the manuscript. The studies were funded by CytRx Corporation, with additional support from an FDA Orphan Drug Product Grant.

Open Access This article is distributed under the terms of the Creative Commons Attribution Noncommercial License which permits any noncommercial use, distribution, and reproduction in any medium, provided the original author(s) and the source are credited.

\section{References}

1. Moloughney JG, Weisleder N. Poloxamer 188 (p188) as a membrane resealing reagent in biomedical applications. Recent Pat Biotechnol. 2012;6(3):200-11.

2. Maskaarinec $\mathrm{S}, \mathrm{Wu} \mathrm{G}$, Lee $\mathrm{K}$. Membrane sealing by poloxamers. Ann N.Y. Acad Sci. 1066;2005:310-20.

3. Marks JD, Pan CY, Bushell T, Cromie W, Lee RC. Amphiphilic, tri-block copolymers provide potent membrane-targeted neuroprotection. FASEB J. 2001;15(6):1107-9.

4. Manno S, Takakuwa Y, et al. Identification of a functional role for lipid asymmetry in biological membranes: phosphatidylserine-skeletal protein interactions modulate membrane stability. Proc Natl Acad Sci USA. 2002;99(4):1943-8.

5. Wolfs JL, Comfurius P, et al. Influence of erythrocyte shape on the rate of $\mathrm{Ca}^{2+}$-induced scrambling of phosphatidylserine. Mol Membr Biol. 2003;20(1):83-91.

6. Curry D, Wright D, Lee R, Kang U, Frim D. J. Neurosurg. 2004;101:(1 Suppl) 91-6.

7. Hunter R, Luo A, Zhang R, Kozar r, Moore F. Poloxamer 188 inhibition of ischemia reperfusion injury: evidence for a novel anti-adhesion mechanism. Ann Clin Lab Sci. 2010;40:(2)115.

8. Unpublished data, Mast therapeutics.

9. Barwal I, Sood A, Sharma M, Singh B, Yadav SC. Development of stevioside Pluronic-F-68 copolymer based PLA-nanoparticles as an antidiabetic nanomedicine. Colloids Surf B Biointerfaces. 2013:1(101):510-6.

10. Zhang B, Mallapragada S. The mechanism of selective transfection mediated by pentablock copolymers; part II: nuclear entry and endosomal escape. Acta Biomater. 2011;7(4):1580-7.

11. Yasuda A, Townsend D, Michele D, Favre E, Day S, Metzger J. Dystrophic heart failure blocked by membrane sealant poloxamer. Nature 2005;436:(18)1025-1029.

12. Juneman E, Saleh L, Lancaster J, Thai H, Markhan B, Goldman $\mathrm{S}$. The effects of poloxamer 188 on left ventricular function in chronic heart failure after myocardial infaction. J Cardiovasc Pharmacol. 2012;60:(3)293-8.

13. Baskaran H, Toner M, Yarmush M, Berthiaume F. Poloxamer 188 improves capillary blood flow and tissue viability in a cutaneous burn wound. J Surg Res. 2001;101(1):56-61.

14. Murphy A, McCormack M, Bichara B, Randolf W, Austen W. Poloxamer 188 significantly decreases muscle necrosis in a murine hindlimb model of ischemia reperfusion injury. J Surg Res. 2009;151(2):220-1.

15. Hunter RL, Papadea C, Gallagher CJ, Finlayson DC, Check IJ. Increased whole blood viscosity during coronary artery bypass surgery. Studies to evaluate the effects of soluble fibrin and poloxamer 188. Thromb Haemost. 1990;63(1):6-12.

16. Grover FL, Kahn RS, Heron MW, Paton BC. A nonionic surfactant and blood viscosity. Experimental observations. Arch Surg. 1973;106(3):307-10.

17. Gaehtgens P, Benner KU. Desaggregation of human red blood cells by various surface-active agents as related to changes of cell shape and hemolysis. Acta Haematol. 1975;53(2):82-9.
18. Carter C, Fisher TC, Hamai H, Johnson CS, Meiselman HE, Nah GB, Stuart J. Haemorheological effects of a nonionic copolymer surfactant (poloxamer 188). Clin Hemorheol. 1992;12:109-20.

19. Hunter RL, Bennett B, Check IJ. The effect of poloxamer 188 on the rate of in vitro thrombolysis mediated by t-PA and streptokinase. Fibrinolysis. 1990;4:117-23.

20. Carr ME Jr, Powers PL, Jones MR. Effects of poloxamer 188 on the assembly, structure and dissolution of fibrin clots. Thromb Haemost. 1991;66(5):565-8.

21. Justicz A, Farnsworth W, Soberman M, Tuvlin G, Bonner R, Hunter R, Martino-Saltzman D, Sink J, Austin G. Reduction of myocardial infarct size by poloxamer 188 and mannitol in a canine model. Am Heart J. 1991;122:671-80.

22. Schaer GL, Hursey TL, Abrahams SL, Buddemeier K, Ennis B, Rodriguez ER, Hubbell JP, Moy J, Parrillo JE. Reduction in reperfusion-induced myocardial necrosis in dogs by RheothRx injection (poloxamer 188, N.F.), a hemorheological agent that alters neutrophil function. Circulation. 1994;90:2964-75.

23. Robinson KA, Hunter RL, Stack JE, Hearn JA, Apkarian RP, Roubin GS. Inhibition of coronary arterial thrombosis in swine by infusion of poloxamer 188. J Invas Cardiol. 1990;2:9-20.

24. O'Keefe JH, Grines CL, DeWood MA, Schaer GL, Browne K, Magorien RD, Kalbfleisch JM, Fletcher WO Jr, Bateman TM, Gibbons RJ. Poloxamer-188 as an adjunct to primary percutaneous transluminal coronary angioplasty for acute myocardial infarction. Am J Cardiol. 1996;78(7):747-50.

25. Burns J, Baer L, Jones J, Dubick M, Wade C. Severe controlled hemorrhage resuscitation with small volume poloxamer 188 in sedated miniature swine. Resuscitation. 2011;82(11):1453-9.

26. Zhang R, Hunter RL, Gonzalez EA, Moore FA. Poloxamer 188 prolongs survival of hypotensive resuscitation and decreases vital tissue injury after full resuscitation. Shock. 2009;32(4): 442-50.

27. Gu JH, Ge JB, Li M, Xu HD, Wu F, Qin ZH. Poloxamer 188 protects neurons against ischemia/reperfusion injury through preserving integrity of cell membranes and blood brain barrier. PLoS One. 2013;8(4):e61641.

28. Adams-Graves P, Kedar A, Koshy M, Steinberg M, Weith K, Ward D, Crawford R, Edwards S, Bustrack J, Emanuele M. RheothRx (Poloxamer 188) injection for the acute painful episode of sickle cell disease: a pilot study. Blood. 1997;90(5):2041-8.

29. Orringer E, Casella J, Ataga K, Koshy M, Adams-Graves P, Luchman-Jones L, Wun T, Watanabe M, Shafer F, Kutlar A, Aboud M, Steinberg M, Adler B, Swerdlow P, Terregino C, Saccente S, Files B, Ballas S, Brown R, Wojtowicz S, Grindel M. Purified Poloxamer 188 for treatment of acute vaso-occlusive crisis of sickle cell disease. JAMA 2001;286(17):2099-106.

30. Schaer GL, Spaccavento LJ, Browne KF, Krueger KA, Krichbaum D, Phelan JM, Fletcher WO, Grines CL, Edwards S, Jolly MK, Gibbons RJ. Beneficial effects of RheothRx injection in patients receiving thrombolytic therapy for acute myocardial infarction. Results of a randomized, double-blind, placebo-controlled trial. Circulation. 1996;94(3):298-307.

31. Effects of RheothRx on mortality, morbidity, left ventricular function, and infarct size in patients with acute myocardial infarction. Collaborative Organization for RheothRx Evaluation (CORE). Circulation. 1997;96(1):192-201.

32. Smith S, Anderson S, Ballermann BJ, Brenner BM. Role of atrial natriuretic peptide in adaptation of sodium excretion with reduced renal mass. J Clin Invest. 1986;77(4):1395-8.

33. Griffin KA, Picken M, Bidani AK. Method of renal mass reduction is a critical modulator of subsequent hypertension and glomerular injury. J Am Soc Nephrol. 1994;4(12):2023-31.

34. Ibrahim HN, Hostetter TH. The renin-aldosterone axis in two models of reduced renal mass in the rat. J Am Soc Nephrol. 1998;9(1):72-6. 
35. Heinegård D, Tiderström G. Determination of serum creatinine by a direct colorimetric method. Clin Chim Acta. 1973;43(3):305-10.

36. Cancer Therapy Evaluation Program. Common terminology criteria for adverse events, version 3.0, DCTD, NCI, NIH, DHHS. March 31, 2003 http://ctep.cancer.gov. Publish Date: 9 Aug 2006.

37. Bendele A, Seely J, Richey C, Sennello G, Shopp G. Short communication: renal tubule vacuolation in animals treated with polyethylene-glycol-conjugated proteins. Toxicol Sci. 1998; 42(2):152-7.

38. Rudmann DG, Alston JT, Hanson JC, Heidel S. High molecular weight polyethylene glycol cellular distribution and PEG-associated cytoplasmic vacuolation is molecular weight dependent and does not require conjugation to proteins. Toxicol Pathol. 2013;41(7):970-83.
39. Stern ST, Adiseshaiah PP, Crist RM. Autophagy and lysosomal dysfunction as emerging mechanisms of nanomaterial toxicity. Part Fibre Toxicol. 2012;14(9):20.

40. Ahsan N, Palmer BF, Wheeler D, Greenlee RG Jr, Toto RD. Intravenous immunoglobulin-induced osmotic nephrosis. Arch Intern Med. 1994;154(17):1985-7.

41. Schmolka IR. Polyalkylene oxide block copolymers. In: Shick MJ, editor. Nonionic surfactants, vol 1. New York: Macrel Dekker; 1966. p. 30-7.

42. Maskarinec SA, Wu G, Lee KY. Membrane sealing by polymers. Ann NY Acad Sci. 2005;1066:310-20. 